\title{
Structural and electrical properties of strontium barium niobate thin films crystallized by conventional furnace and rapid-thermal annealing process
}

\author{
R.G. Mendes \\ Universidade Federal de São Carlos, Departamento de Física, Grupo de Cerâmicas Ferroelétricas, \\ Caixa Postal 676, 13565-670 São Carlos, SP, Brazil \\ E.B. Araújo ${ }^{\text {a) }}$ \\ Universidade Estadual Paulista, Departamento de Física e Química, Grupo de Vidros e Cerâmicas, \\ Caixa Postal 31, 15385-000 Ilha Solteira, SP, Brazil \\ J.A. Eiras \\ Universidade Federal de São Carlos, Departamento de Física, Grupo de Cerâmicas Ferroelétricas, \\ Caixa Postal 676, 13565-670 São Carlos, SP, Brazil
}

(Received 5 September 2000; accepted August 6, 2001)

\begin{abstract}
Strontium barium niobate (SBN) thin films were crystallized by conventional electric furnace annealing and by rapid-thermal annealing (RTA) at different temperatures. The average grain size of films was $70 \mathrm{~nm}$ and thickness around $500 \mathrm{~nm}$. Using $\mathrm{x}$-ray diffraction, we identified the presence of polycrystalline SBN phase for films annealed from 500 to $700{ }^{\circ} \mathrm{C}$ in both cases. Phases such as $\mathrm{SrNb}_{2} \mathrm{O}_{6}$ and $\mathrm{BaNb}_{2} \mathrm{O}_{6}$ were predominantly crystallized in films annealed at $500{ }^{\circ} \mathrm{C}$, disappearing at higher temperatures. Dielectric and ferroelectric parameters obtained from films crystallized by conventional furnace and RTA presented essentially the same values.
\end{abstract}

\section{INTRODUCTION}

The tungsten bronze family is one of several ferroelectric materials. Since 1949, when the tungsten bronze structure was deduced by Magneli, ${ }^{1}$ numerous tungsten bronzes have been synthesized. The tungsten bronze family includes niobates such as $(\mathrm{Sr}, \mathrm{Ba}) \mathrm{Nb}_{2} \mathrm{O}_{6}(\mathrm{SBN})$, $(\mathrm{Pb}, \mathrm{Ba}) \mathrm{Nb}_{2} \mathrm{O}_{6}(\mathrm{PBN})$, and $(\mathrm{Pb}, \mathrm{K}) \mathrm{Nb}_{2} \mathrm{O}_{6}(\mathrm{PKN})$. $\mathrm{PBN}$ and $\mathrm{PKN}$ are orthorhombic tungsten bronze structure with a point group $m m 2$. On the other hand, SBN $\left(\mathrm{Sr}_{x} \mathrm{Ba}_{1-x} \mathrm{Nb}_{2} \mathrm{O}_{6}\right)$, with $0.25<x<0.75$, presents a tetragonal $(4 \mathrm{~mm})$ phase at room temperature. A solid solution of SBN exists in the binary $\mathrm{SrNb}_{2} \mathrm{O}_{6}-\mathrm{BaNb}_{2} \mathrm{O}_{6}$ system. Investigations using $\mathrm{x}$-ray diffraction (XRD) suggested a morphotropic phase boundary around $x=$ 0.25 , which is characterized by the coexistence of the tetragonal and orthorhombic phases. ${ }^{2}$

The excellent ferroelectric and electro-optic properties exhibited by SBN make this material promising for a variety of applications. SBN has received great attention as a ferroelectric material due to its large pyroelectric coefficient, ${ }^{3}$ piezoelectric, ${ }^{4}$ and electro-optic properties. ${ }^{5}$

\footnotetext{
a) Address all correspondence to this author. e-mail: eudes@fqm.feis.unesp.br
}

In recent years, the development of integrated optical devices has stimulated the demand for thin films using attractive materials such as SBN. SBN thin films have been prepared by several techniques like sol-gel processing, ${ }^{6}$ pulsed laser deposition, ${ }^{7}$ and metalorganic chemical vapor deposition (MOCVD). ${ }^{8}$ Large-scale processing of high-quality thin films requires lowtemperature synthesis, high reproducibility, simplicity in all processing steps, and low cost. Due to this fact, the search for new routes for film preparation remains an interesting and open subject in order to improve the stability of complex solutions, the control of the stoichiometry of the film composition, or to reduce the cost of the process. Very recently, the preparation of SBN thin films by a chemical method based on a polymeric resin containing metallic ions was proposed. ${ }^{9}$ The method was successfully applied to prepare SBN thin films of good quality and homogeneity.

In this work, SBN thin films obtained by the early cited method were studied under its structural, dielectric, and ferroelectric properties. The effect of the different heat treatments on SBN thin films, using conventional furnace and rapid-thermal annealing (RTA), was studied. Dielectric and ferroelectric properties are presented for films crystallized at different temperatures. 


\section{EXPERIMENTAL PROCEDURE}

In this work SBN films were prepared by a hybrid chemical method used to produce a polymeric resin. ${ }^{9}$ The general idea is to distribute the metallic ions homogeneously throughout the polymeric resin, prepared according to the Pechini method. ${ }^{10}$ The process calls for forming a chelate between dissolved ions with a hydroxycarboxylic acid (citric acid). Heating of the resin in air causes a breakdown of the polymer. Subsequently, the ions are oxidized to form the desired crystalline phases.

Barium oxide $(\mathrm{BaO})$, strontium carbonate $\left(\mathrm{SrCO}_{3}\right)$, and ammoniac complex $\left[\mathrm{NH}_{4} \mathrm{H}_{2} \mathrm{NbO}\left(\mathrm{C}_{2} \mathrm{O}_{4}\right) \cdot 3 \mathrm{H}_{2} \mathrm{O}\right]$ were selected as starting materials. The molar ratio of starting materials was calculated to obtain a final $\mathrm{Sr}_{0.75} \mathrm{Ba}_{0.25} \mathrm{Nb}_{2} \mathrm{O}_{6}$ (SBN 75/25) composition. For preparation of the resin, $\mathrm{BaO}, \mathrm{SrCO}_{3}$, and $\mathrm{NH}_{4} \mathrm{H}_{2} \mathrm{NbO}\left(\mathrm{C}_{2} \mathrm{O}_{4}\right) \cdot 3 \mathrm{H}_{2} \mathrm{O}$ were initially dissolved in water to form a transparent solution. Next, each solution was mixed separately with citric acid and heated to $40{ }^{\circ} \mathrm{C}$ for $30 \mathrm{~min}$. This stage is important to form chelate between mixed cations with a hydroxycarboxylic acid (citric acid). Then, each solution was mixed with ethylene glycol (citric acid/ethylene glycol $=50 / 50$ ) and polymerized by heating up to $100{ }^{\circ} \mathrm{C}$ for $30 \mathrm{~min}$. Finally, the three solutions were mixed at room temperature and heated again to $50{ }^{\circ} \mathrm{C}$ and stirred during 20 min to homogenization, when a transparent resin was obtained. The final transparent resin indicates that all metallic ions were distributed throughout the polymeric resin.

Films of the resins were deposited at room temperature on $\mathrm{Pt} / \mathrm{Si}$ substrates by spin coating at $4500 \mathrm{rpm}$ for $40 \mathrm{~s}$. Films were obtained by depositing multiple layers of this resin. Each layer was annealed at $400{ }^{\circ} \mathrm{C}$ for $3 \mathrm{~h}$ to remove organic material. The process was repeated for eight deposited layers to obtain a dense film. Deposited films were crack free, uniform, and well adhered on substrates. For crystallization, films deposited on $\mathrm{Pt} / \mathrm{Si}$ substrates were annealed in a conventional electric furnace at 500,600 , and $700{ }^{\circ} \mathrm{C}$ for $1 \mathrm{~h}$. The rapid-thermal crystallization was carried out in a Research INC power controller Model 664F RTA furnace at 500, 600, and $700{ }^{\circ} \mathrm{C}$ for $60 \mathrm{~s}$. This RTA process permits heating rates between 10 to $50{ }^{\circ} \mathrm{C} / \mathrm{s}$.

The structure of the crystallized films at different temperatures was analyzed by XRD using $\mathrm{Cu} \mathrm{K}_{\alpha}$ radiation at room temperature. The morphological examination of SBN films was performed on a JEOL JSM-5800 (Tokyo, Japan) scanning electron microscope (SEM). The dielectric constant $(\epsilon)$ and dissipation factor $(\tan \delta)$ were measured from $500-$ to $500-\mathrm{kHz}$ frequency using an HP 4194A impedance analyzer. A SawyerTower circuit was used to measure the ferroelectric properties at $100 \mathrm{~Hz}$.

\section{RESULTS AND DISCUSSION}

SBN films of good quality were obtained in this work. Figure 1 shows an SEM photomicrograph of the crosssectional view of SBN thin film deposited on Pt/Si substrate. This film was crystallized at $700{ }^{\circ} \mathrm{C}$ for $1 \mathrm{~h}$ using a conventional furnace. Based on Fig. 1, measured thickness of the film was $500 \mathrm{~nm}$ and grain size was around 70 $\mathrm{nm}$, on average.

The effect of temperature crystallization in SBN films was investigated under different conditions. Figure 2 shows XRD patterns for SBN films crystallized by conventional furnace and RTA process. Peaks identified in this figure were attributed to tetragonal SBN phase. As shown in Fig. 2, polycrystalline SBN phase crystallizes better on films annealed at 600 and $700{ }^{\circ} \mathrm{C}$ for $1 \mathrm{~h}$. Some structural fluctuation can be seen for films annealed at $500{ }^{\circ} \mathrm{C}$ [Fig. 2(A)] when the well-defined (211) and (400) peaks were observed. These peaks disappear for films crystallized at $600{ }^{\circ} \mathrm{C}$ [Fig. 2(B)] and $700{ }^{\circ} \mathrm{C}$ [Fig. 2(C)].

Based on XRD patterns, changes of full width at halfmaximum (FWHM) for some $(h k l)$ peaks represent the degree of crystallization as a function of annealing temperature. The FWHMs of (311) peak in Fig. 2 were $0.72^{\circ}, 0.63^{\circ}$, and $0.57^{\circ}$ for films respectively annealed at 500,600 , and $700{ }^{\circ} \mathrm{C}$ for $1 \mathrm{~h}$. These facts show that when annealing temperature increases the crystallization of $\mathrm{SBN}$ films on $\mathrm{Pt} / \mathrm{Si}$ is improved. In Fig. 2(A) we can also identify the presence of the $\mathrm{SrNb}_{2} \mathrm{O}_{6}(\mathrm{SN})$ and $\mathrm{BaNb}_{2} \mathrm{O}_{6}(\mathrm{BN})$ phases for films annealed at $500{ }^{\circ} \mathrm{C}$ for $1 \mathrm{~h}$. When temperature increases, $\mathrm{BN}$ disappears but $\mathrm{SN}$ remains at film annealed at 600 and $700{ }^{\circ} \mathrm{C}$ for $1 \mathrm{~h}$. Neither SN nor BN is a ferroelectric material with the tungsten bronze structure. They are components of the solid solution that yields ferroelectric SBN.

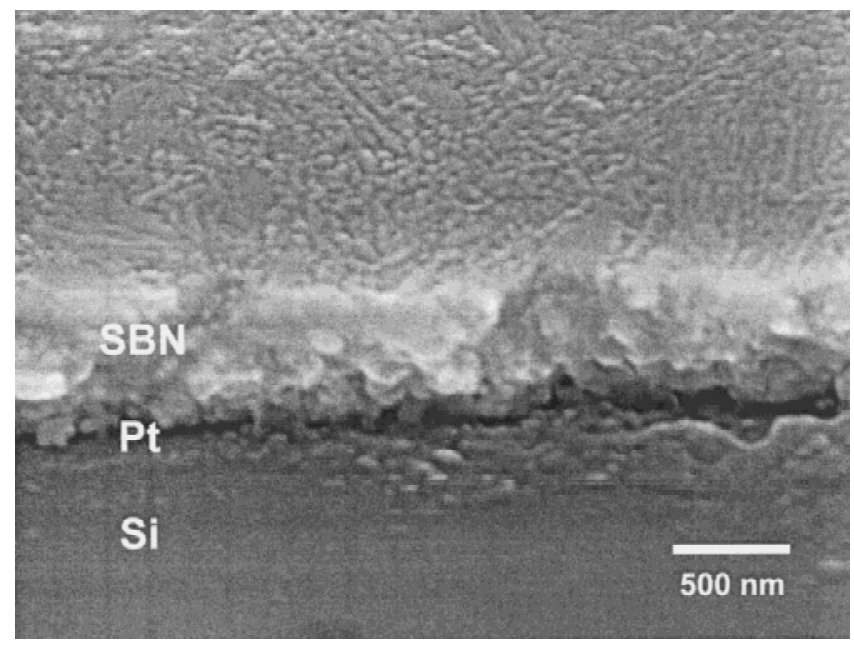

FIG. 1. Cross section of SBN thin film deposited on Pt/Si substrate and crystallized by a conventional furnace at $700{ }^{\circ} \mathrm{C}$ for $1 \mathrm{~h}$. 
Figure 2(D) shows XRD patterns of the SBN films crystallized by RTA at $700{ }^{\circ} \mathrm{C}$ for $60 \mathrm{~s}$. The FWHM of the (311) peak was $0.57^{\circ}$, indicating similar behavior of SBN film crystallized by conventional method at same temperature. As observed in Fig. 2(D), SBN was crystallized without SN phase and this may be attributed to effective crystallization of the SBN phase using the RTA process. Films were also crystallized at 500 and $600{ }^{\circ} \mathrm{C}$ for $60 \mathrm{~s}$ using RTA, not shown here. These films presented essentially the same results, in terms of crystallization, as films crystallized in a conventional furnace at the same temperatures.

Based on XRD patterns of SBN films crystallized at $700{ }^{\circ} \mathrm{C}$ by conventional and RTA methods, the lattice constants $a$ and $c$ were calculated for tetragonal phase using the (001), (311), (002), and (322) peaks. For the film annealed by the conventional method, the calculated lattice constants were $a=11.57 \AA$ and $c=4.00 \AA$, while $a=11.62 \AA$ and $c=4.03 \AA$ for film crystallized by RTA. The lattice parameters $a$ and $c$ obtained here

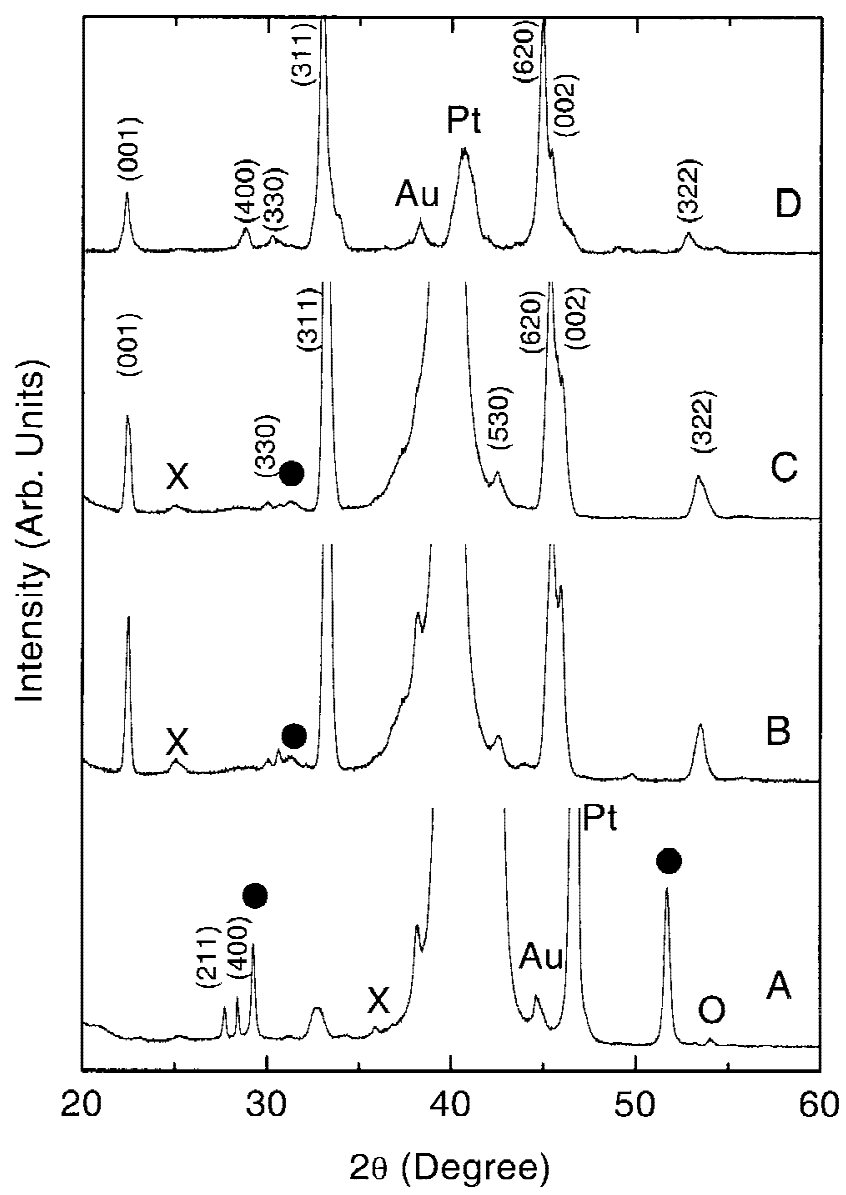

FIG. 2. XRD patterns of SBN thin films deposited on Pt/Si substrate. Films were crystallized by conventional furnace at (A) $500{ }^{\circ} \mathrm{C}$, (B) $600{ }^{\circ} \mathrm{C}$, and $(\mathrm{C}) 700^{\circ} \mathrm{C}$ for $1 \mathrm{~h}$ and (D) by RTA process at $700{ }^{\circ} \mathrm{C}$ for $60 \mathrm{~s}$. Symbols represent $(\times)$ unidentified phase, $(\bullet) \mathrm{SrNb}_{2} \mathrm{O}_{6}$, and $(\bigcirc)$ $\mathrm{BaNb}_{2} \mathrm{O}_{6}$. agreed relatively well with results of the literature for SBN 75/25 thin film obtained by MOCVD, whose values are around $a=12.430 \AA$ and $c=3.932 \AA{ }^{8}$ For bulk crystals with the same composition the lattice parameters are $a=12.458 \AA$ and $c=3.928 \AA^{11}$

Films annealed at $700{ }^{\circ} \mathrm{C}$ by the conventional method (for $1 \mathrm{~h}$ ) and RTA (for $60 \mathrm{~s}$ ) were used for dielectric and ferroelectric measurements because these films presented better crystallization. The dielectric behavior of the SBN films, examined in terms of the dielectric constant $(\epsilon)$ dissipation factor $(\tan \delta)$ as functions of measuring frequency, are summarized in Fig. 3.

It may be seen that dielectric constant exhibits a slight frequency dependency, which is consistent with the expected normal behavior. The dielectric constant and dissipation factor at a frequency of $100 \mathrm{kHz}$ were 119 and 0.164 , respectively, for film crystallized by the conventional method at $700{ }^{\circ} \mathrm{C}$ for $1 \mathrm{~h}$. For film crystallized using the RTA method these values were respectively 107 and 0.088 . The value of the dielectric constant obtained here is consistent with other reports for SBN thin films obtained through metal alkoxide. ${ }^{12}$ The observed frequency dispersion at lower frequencies of the dissipation factor $(\tan \delta)$ is probably related to interfacial effects, often denominated the Maxwell-Wagner type.

Hysteresis loops were observed at room temperature, at $100 \mathrm{~Hz}$. Figure 4 shows P-E hysteresis loop of SBN films crystallized by conventional furnace at $700{ }^{\circ} \mathrm{C}$ for $1 \mathrm{~h}$ and by RTA at $700{ }^{\circ} \mathrm{C}$ for $60 \mathrm{~s}$. Rounded curves were found due to the low-frequency high-loss characteristics of the films. The remanent polarization $\left(\mathrm{P}_{\mathrm{r}}\right)$ and the coercive field $\left(\mathrm{E}_{\mathrm{c}}\right)$ were $17.8 \mu \mathrm{C} / \mathrm{cm}^{2}$ and $180 \mathrm{kV} / \mathrm{cm}$, respectively, for the SBN film annealed in a conventional furnace at $700{ }^{\circ} \mathrm{C}$ for $1 \mathrm{~h}$. Similar results were obtained for films crystallized by the RTA method. This film presented $\mathrm{P}_{\mathrm{r}}=16 \mu \mathrm{C} / \mathrm{cm}^{2}$ and $\mathrm{E}_{\mathrm{c}}=155 \mathrm{kV} / \mathrm{cm}$. In the literature, reported values of $\mathrm{P}_{\mathrm{r}}$ and $\mathrm{E}_{\mathrm{c}}$ for $\mathrm{SBN} 75 / 25$ films ranged from 1.9 to $34 \mu \mathrm{C} / \mathrm{cm}^{2}$ and 51 to $180 \mathrm{kV} / \mathrm{cm}$,

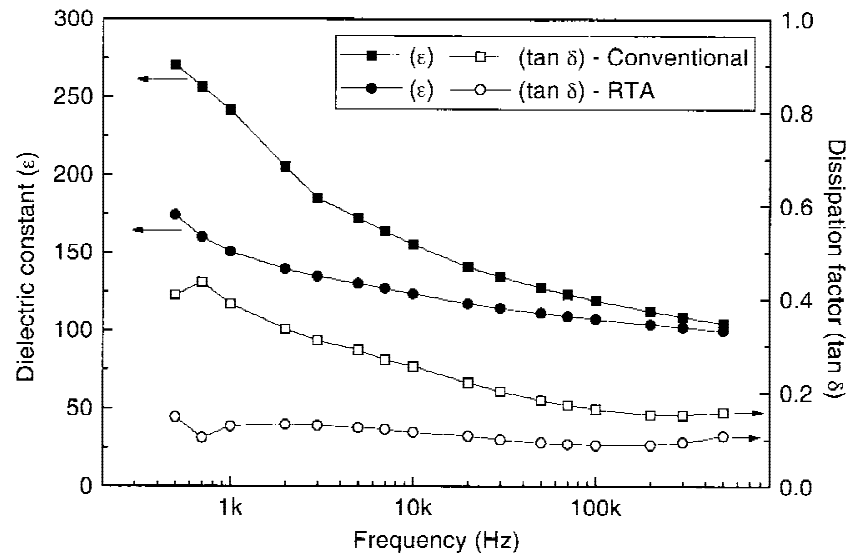

FIG. 3. Dielectric constant and dissipation factor for SBN thin films crystallized by conventional and RTA methods. 
respectively, obtained by sol-gel. ${ }^{12,13}$ In this work, the observed $\mathrm{P}_{\mathrm{r}}$ is lower if compared with values observed for crystals, whose values ranged from 27 to $32 \mu \mathrm{C} / \mathrm{cm}^{2} .{ }^{11}$ However, the coercive field $\left(\mathrm{E}_{\mathrm{c}}\right)$ and remanent polarization $\left(\mathrm{P}_{\mathrm{r}}\right)$ values obtained here for SBN thin films may not correspond to intrinsic values because the conductivity effect was not discounted in loop hysteresis of Fig. 4. Thus, the distortion observed on hysteresis is probably associated with the effect of conductivity in SBN films, which may be attributed to the presence of undesirable coexistence of phases on films such as $\mathrm{Sr}_{0.75} \mathrm{Ba}_{0.25} \mathrm{Nb}_{2} \mathrm{O}_{6}(\mathrm{SBN} 75 / 25)$ and $\mathrm{SrNb}_{2} \mathrm{O}_{6}(\mathrm{SN})$.

The capacitance-voltage $(\mathrm{C}-\mathrm{V})$ characteristic was also studied on films crystallized at $700{ }^{\circ} \mathrm{C}$. A small alternating-current signal of $10-\mathrm{mV}$ amplitude and $100-\mathrm{kHz}$ frequency was applied across the sample while the direct-current electric field was swept from positive

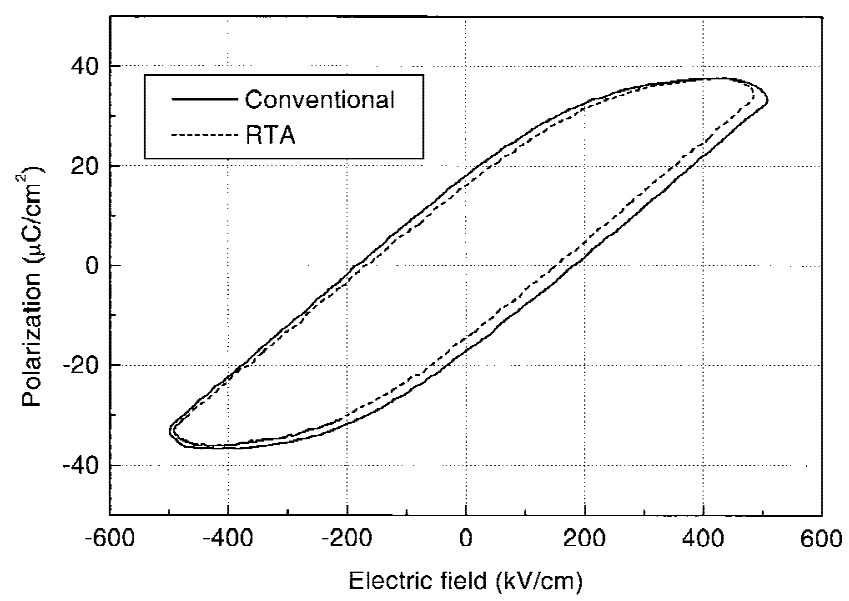

FIG. 4. Hysteresis loop, measured at $100 \mathrm{~Hz}$, of SBN film annealed by a conventional furnace at $700{ }^{\circ} \mathrm{C}$ for $1 \mathrm{~h}$ and RTA at $700{ }^{\circ} \mathrm{C}$ for $60 \mathrm{~s}$.

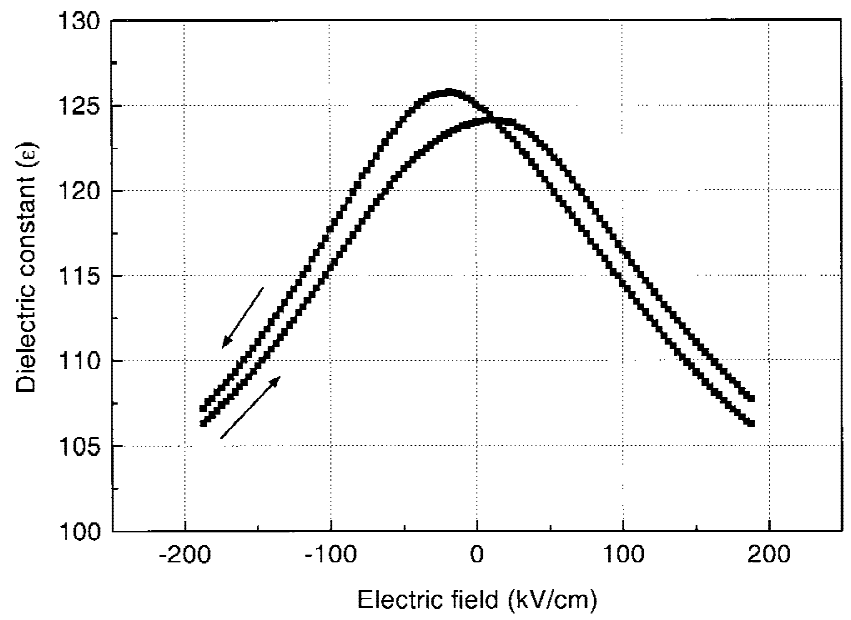

FIG. 5. C-V characteristic of SBN thin film crystallized by a conventional furnace at $700{ }^{\circ} \mathrm{C}$ for $1 \mathrm{~h}$. bias to negative bias and back again. Figure 5 shows the $\mathrm{C}-\mathrm{V}$ characteristic of the film crystallized by the conventional furnace; film prepared by RTA presented a similar result. The two maximas, which are due to ferroelectric polarization reversals, associated with double coercive field $\left(\mathrm{E}_{\mathrm{c}}\right)$, are clearly seen in Fig. 5. Generally the coercive field determined by $\mathrm{C}-\mathrm{V}$ measurements are somewhat smaller than $\mathrm{E}_{\mathrm{c}}$ determined from the hysteresis loop measurements due to dependence of $\mathrm{E}_{\mathrm{c}}$ on the applied voltage and frequency. Note that the two peaks are of different height and there is a small offset toward positive bias. Considering a ferroelectric, the polarization and dielectric constant vary nonlinearly with applied field. In some cases, a space charge is formed at interfaces and, under conditions of reverse bias, a depletion layer forms. ${ }^{14}$ Asymmetry and shift in $\mathrm{C}-\mathrm{V}$ curve may be observed if a disparity of the space charge occurs. In general, observed effects are associated with contacts and may be minimized with adequate postannealing of the films.

\section{CONCLUSIONS}

Polycrystalline SBN thin films of high density were crystallized on $\mathrm{Pt} / \mathrm{Si}$ substrates using a polymeric resin. Results showed good crystallization of SBN films, crystallized using a conventional furnace or RTA. Undesired phases such as $\mathrm{SrNb}_{2} \mathrm{O}_{6}$ and $\mathrm{BaNb}_{2} \mathrm{O}_{6}$ appear in films deposited at $500{ }^{\circ} \mathrm{C}$ but these phases disappear at higher temperatures. Finally, dielectric and ferroelectric parameters presented essentially the same values for films crystallized by a conventional furnace and RTA. Thus, for purposes of future applications in microelectronic devices, the preparation of SBN films by the RTA method is of interest. In this case, the final product will be less expensive than other SBN thin films produced by other physical methods. The main and distinct advantage over other chemical methods, especially sol-gel, is associated with the high stability observed in polymeric resin used on film deposition. Previous stability investigations showed that these resins could be used after 1 year without appreciable changes in structural, microstructural, and electric characteristics of the films. The next step is to study ideal conditions to eliminate or minimize undesirable observed effects in dielectric characteristics of the SBN films.

\section{ACKNOWLEDGMENTS}

The authors are grateful to C-N-P-q and F-A-P-E-S-P (processes 98/16513-5 and 99/02485-2) for financial support, to Dr. Yvonne P. Mascarenhas (I-F-S C-U-S-P) for XRD facilities, and to Mr. Francisco J. Picon (D-F - U-F-S-C-a-r) for technical support. 


\section{REFERENCES}

1. A. Magneli, Ark. Kemi 1, 213 (1949).

2. S. Nishiwaki, J. Takahashi, K. Kodaira, and M. Kishi, Jpn. J. Appl. Phys. 35, 5137 (1996).

3. A.M. Glass, J. Appl. Phys. 40, 4699 (1969).

4. J.D. Zook and S.T. Liu, J. Appl. Phys. 49, 4604 (1978).

5. M. Horowitz, A. Bekker, and B. Fischer, Appl. Phys. Lett. 62, 2619 (1993).

6. Y. Xu, C.J. Chen, R. Xu, and J.D. Mackenzie, Phys. Rev. B 44, 35 (1991).

7. S.S. Thöny, K.E. Youden, J.S. Harris, Jr., and L. Hesselink, Appl. Phys. Lett. 65, 2018 (1994).

8. M. Lee and R.S. Feigelson, J. Cryst. Growth 180, 220 (1997).
9. R.G. Mendes, E.B. Araújo, H. Klein, and J.A. Eiras, J. Mater. Sci. Lett. 18, 1941 (1999).

10. P.A. Lessing, Ceram. Bull. 68, 1002 (1989).

11. R.R. Neurgaonkar, W.F. Hall, J.R. Oliver, W.W. Ho, and W.K. Cory, Ferroelectrics 87, 167 (1988).

12. W. Sakamoto, T. Yogo, K. Kikuta, K. Ogiso, A. Kawase, and S. Hirano, J. Am. Ceram. Soc. 79, 2283 (1996).

13. C.J. Chen, Y. Xu, R. Xu, and J.D. Mackenzie, J. Appl. Phys. 69, 1763 (1991).

14. J.M. Bell, P.C. Knight, and G.R. Johnston, in Ferroelectric Thin Films: Synthesis and Basic Properties, edited by C. Paz de Araujo, J.F. Scott, and G.W. Taylor (Gordon and Breach Science Publishers, Amsterdam, The Netherlands, 1996), p. 116. 